\title{
Development and Validation of RP-HPLC Method for the Determination of Hydrochlorothiazide in Bulk Drug and Pharmaceutical Dosage Form
}

\author{
Nidhal S. Mohammed and Ahmed J. Mohammed \\ School of Chemistry, Faculty of Science, University of Zakho, Zakho City, Kurdistan of Iraq, Iraq \\ Correspondence should be addressed to Nidhal S. Mohammed; nidhalsher@yahoo.com
}

Received 27 April 2016; Revised 14 July 2016; Accepted 2 August 2016

Academic Editor: Susana Casal

Copyright @ 2016 N. S. Mohammed and A. J. Mohammed. This is an open access article distributed under the Creative Commons Attribution License, which permits unrestricted use, distribution, and reproduction in any medium, provided the original work is properly cited.

\begin{abstract}
An HPLC-PDA method was developed and validated for the determination of hydrochlorothiazide in bulk and pharmaceutical formulation. The method was optimized selecting chromatographic conditions of 50:50 acetonitrile : water, Inertsil ${ }^{\circledR}$ column (ODS$3250 \mathrm{~mm} \times 4.6 \mathrm{~mm} 5 \mu \mathrm{m}), 20 \mu \mathrm{L}$ injection volume, flow rate of $1 \mathrm{~mL} / \mathrm{min}$ at ambient temperature $\left(30^{\circ} \mathrm{C}\right)$, and $272 \mathrm{~nm}$. Another column of $\mathrm{C}_{18}$ Zorbax $^{\circledR}$ (Eclipse Plus, $4.6 \times 250 \mathrm{~mm}, 5 \mu \mathrm{m}$ ) was tested showing no big difference in the method results. The method was validated giving good precision ( $\mathrm{RSD} \%<1)$, acceptable linearity $\left(R^{2} \geq 0.9978\right)$, and low LOD and LOQ $(0.5 \mathrm{and} 1.7 \mu \mathrm{g} / \mathrm{mL}$, resp.) on both columns. Successful application on pharmaceutical dosage tablet form gave high recovery of $99.93 \%$. The method was compared with official BP and other reported methods. The proposed method is economic, simple, and rapid and hence can be employed for routine analysis in quality control laboratories.
\end{abstract}

\section{Introduction}

Hydrochlorothiazide chemical name is $2 \mathrm{H}-1,2,4$-Benzothiadiazine-7-sulfonamide,6-chloro3,4-dihydro-,1,1-dioxide (Figure 1). It is slightly soluble in water and sparingly soluble in acetonitrile. Hydrochlorothiazide belongs to a class of drugs called thiazide diuretics antihypertensive [1]. Hydrochlorothiazide binds to and inhibits the enzyme carbonic anhydrase. It is frequently used alone or in combination with other medications for the treatment of hypertension, congestive heart failure, symptomatic edema, diabetes insipidus, renal tubular acidosis, hypoparathyroidism, and edema and prevention of kidney stones and used in the treatment of osteoporosis [2].

An extensive literature survey was carried out and found that there are few analytical methods for the determination of hydrochlorothiazide alone or in its combination with other drugs in pharmaceutical preparations including spectrophotometry [3, 4], flow injection [5], TLC [6], and HPLC [7-9]. A recent study involved a review of developing methods using these analytical techniques for estimation of hydrochlorothiazide in various biological samples with focus on sample pretreatment methods and separation methods [10].

In this study, an attempt was made to develop new HPLC method for hydrochlorothiazide estimation in bulk and pharmaceutical formulation with good precision, accuracy, linearity, and reproducibility using two columns $\mathrm{C}_{18}$ Inertsil $^{\circledR}$ ODS- 3 and $\mathrm{C}_{18}$ Zorbax Eclipse Plus.

Nowadays, HPLC columns packed with a stationary phase of $\mathrm{C}_{18}$-bonded silica are produced by many manufactures in different parts of the world for the separation of many organic compounds. $\mathrm{C}_{18}$ columns from different manufacturers, but with the same bonded phase, may provide different separation selectivity for many separation components [11]. Even differences between columns provided by the same manufacturers have been reported [12].

\section{Materials and Methods}

2.1. HPLC System. Analytical HPLC system comprised a Flexar autosampler injector-no Peltier, Flexar Binary pump, 


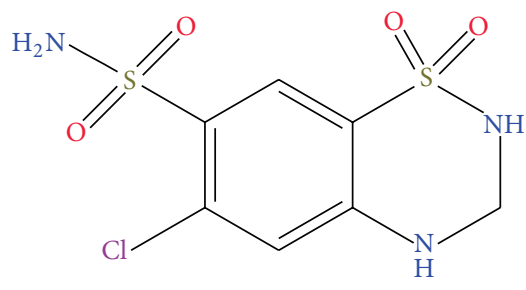

FIGURE 1: The chemical structure of hydrochlorothiazide.

Inertsil (ODS-3 $250 \mathrm{~mm} \times 4.6 \mathrm{~mm}, 5 \mu \mathrm{m}$ siloxane), and a Flexar/S275/S200EP Photo Diode Array Detector coupled with chromera ${ }^{\circledR}$ version 3.4.0.5712 software. Flexar column oven was connected with a system to control the column temperature. Column of Zorbax ${ }^{\circledR}$ Eclipse Plus $(4.6 \times 250 \mathrm{~mm}$, $5 \mu \mathrm{m}$ ) was used as well.

2.2. Chemicals. Pharmaceutically pure sample of HCTZ drug was obtained from Awamedica Company (in Erbil city, Kurdistan region of Iraq). Commercial tablet of HCTZ (100 mg) was procured from the local drug market. Acetonitrile and water were HPLC from merck KGaA, 64271 Darmstadt, Germany.

2.2.1. Preparation the Mobile Phase. The mobile phase of HPLC analysis was prepared from organic solvent of acetonitrile and water (v:v\%) $(50 \%, 60 \%$, and $70 \%$ of $\mathrm{ACN})$. The mobile phase was degassed using an ultrasonic bath $(100 \mathrm{~W}$, $80 \mathrm{KHz}$, Elmasonic P, Germany.).

2.2.2. Stock and Working Solutions. Stock solution of $1000 \mu \mathrm{g} / \mathrm{mL}$ of HCTZ was prepared by dissolving $0.1 \mathrm{~g}$ of sample in $100 \mathrm{~mL}$ of acetonitrile. This stock standard solution was stored in a refrigerator and used to prepare the working solutions at different concentrations.

2.2.3. Sample Solution Preparation. Ten tablets were crushed to fine powder. An accurately weighed portion of the powder (equivalent to $20 \mu \mathrm{g} / \mathrm{mL}$ ) was taken and dissolved in $100 \mathrm{~mL}$ of acetonitrile.

2.3. Determination of Maximum Absorption of HCTZ. A UV-Visible Double beam Spectrophotometer (200-700 nm, Lambda 25, Perkin Elmer, USA) was used to measure the wavelength $\left(\lambda_{\max }\right)$ at maximum absorbance for HCTZ in acetonitrile in the range $200-400 \mathrm{~nm}$ analysing $10 \mu \mathrm{g} / \mathrm{mL}$ standard solution of HCTZ.

\subsection{Development and Optimization of the HPLC Method}

2.4.1. The Effect of Different Strengths of the Mobile Phase. To construct a basic background for developing an HPLC method with fast analysis for the determination of HCTZ, the effect of the different concentrations of the mobile phase was investigated. Isocratic elution run was employed by analysing solution of $10 \mu \mathrm{g} / \mathrm{mL}$ at different strengths of the mobile phase $(50 \%, 60 \%$, and $70 \%(\mathrm{v} / \mathrm{v}))$ of ACN. The chromatographic conditions were set using a $20 \mu \mathrm{L}$ injection volume, flow rate of $1.0 \mathrm{~mL} / \mathrm{min}$, column oven at ambient temperature $\left(30^{\circ} \mathrm{C}\right)$, and UV detection at a wavelength of $272 \mathrm{~nm}$.

2.4.2. The Effect of Injection Volume. The effect of injection volume was examined as parameter that may affect peak elution during method development. Three injection volumes were tested including 10,20 , and $30 \mu \mathrm{L}$ using solution of $10 \mu \mathrm{g} / \mathrm{mL}$ at $50 \%$ ACN mobile phase.

2.4.3. The Effect of Column Temperature. Three different temperatures of $40^{\circ} \mathrm{C}, 35^{\circ} \mathrm{C}$, and ambient temperature $\left(30^{\circ} \mathrm{C}\right)$ were tested to study the effect of the column oven temperature analysing $10 \mu \mathrm{g} / \mathrm{mL}$ of HCTZ at $50 \%$ ACN mobile phase.

2.4.4. The Effect of Different Columns. The effect of the different column brands on the optimization of HCTZ peak was investigated using two columns $\mathrm{C}_{18}$ Inertsil ODS-3 (4.6× $250 \mathrm{~mm}, 5 \mu \mathrm{m})$ and $\mathrm{C}_{18}$ Zorbax Eclipse Plus $(4.6 \times 250 \mathrm{~mm}$, $5 \mu \mathrm{m})$.

\subsection{Method Validation}

2.5.1. Assessment of the Precision of Method. The precision of the HPLC analytical method was estimated by repeated injections $(n=5)$ of $5 \mu \mathrm{g} / \mathrm{mL}$ solution of HCTZ using two columns ( $\mathrm{C}_{18}$ Inertsil column and $\mathrm{C}_{18}$ Zorbax column) calculating relative standard deviation (RSD\%) of the peak area of HCTZ on each column.

2.5.2. Linearity Assessment. Linearity of the calibration curve was determined at two ranges $(2-10$ and $10-30 \mu \mathrm{g} / \mathrm{mL})$ preparing five different concentrations at each range. Linearity was determined using two columns $\left(\mathrm{C}_{18}\right.$ Inertsil and $\mathrm{C}_{18}$ Zorbax columns). Aliquots of these solutions $(20 \mu \mathrm{L})$ were injected into the analytical HPLC system and the detector response (peak area) was plotted against the nominated concentration to generate the calibration curve. Using Excel ${ }^{\circledR}$ software, from the regression line, the coefficient of determination $\left(R^{2}\right)$ was obtained to statistically assess the linear relationship.

2.5.3. Limit of Detection and Limit of Quantification. The limit of detection (LOD) and limit of quantification (LOQ) of HCTZ in solution were calculated using two columns based on the data from the lower range of the calibration curve [13]. The calibration curve at low levels of HCTZ was used to statistically estimate the HCTZ peak area, which was significantly different from the blank peak area. The equation used to estimate this peak area was

$$
\text { LOD peak area }=y_{B}+3 s_{B}
$$

where $y_{B}$ is the blank peak area and $s_{B}$ is the standard deviation of the blank peak area. In practice, the value of $y_{B}$ and $s_{B}$ can be estimated from the calibration graph at the lower range by using values from the regression analysis of variance. Therefore, the value of $y_{B}$ was replaced by the intercept value of the regression equation of the calibration graph of HCTZ at the lower range of $2-10 \mu \mathrm{g} / \mathrm{mL}$. Similarly, 
the term $s_{B}$ was replaced by the residual standard deviation, which is the square root of the error mean square. Both terms were estimated using the regression function in Excel software. The statistical data consist of the intercept, slope, and standard deviation of the regression line (SD); after calculating the LOD and the LOQ peak area depending on the above information of the regression line, the LOD and the LOQ were determined according to the following equations:

LOD Peak area $=$ intercept $+3 \mathrm{SD}$,

$$
\mathrm{LOD}=\frac{(\text { LOD Peak area }- \text { intercept })}{\text { slope }},
$$

LOQ Peak area $=$ intercept +10 SD,

$$
\mathrm{LOQ}=\frac{(\text { LOQ Peak area }- \text { intercept })}{\text { slope }} .
$$

2.5.4. Application of the Method to Dosage Form. The accuracy of proposed method was ascertained on the basis of average recovery \% to determine HCTZ in its pharmaceutical preparation as tablets (equivalent to $20 \mu \mathrm{g} / \mathrm{mL}$ ) by triplicate injections under the same chromatographic conditions of the proposed method. The recovery was calculated according to the following:

$$
\text { Recovery } \%=\frac{(\text { Recovered amount } \times 100)}{\text { Injected amount }} \text {. }
$$

\section{Results and Discussion}

3.1. Determination of Maximum Absorption of HCTZ. In HPLC-UV methods, selecting a wavelength that is not close to the $\lambda_{\max }$ of the studied compound can produce low sensitivity and nonlinearity measurements of response. Therefore, all the measurements should be determined at the $\lambda_{\max }$ of the studied compound to obtain a high response for its peak. Using solution of HCTZ prepared in acetonitrile solvent showed strong UV absorbance at the optimum wavelength of $272.07 \mathrm{~nm}$ as shown in Figure 2. Reviewing the literature, the obtained wavelength is confirmed in different studies [4, 1416].

3.2. Development and Optimization of the HPLC Method. The basic chromatographic conditions were selected after testing different parameters that influence the HPLC analysis of HCTZ, such as the strength of mobile phase, injection volume, column temperature, and different column manufactures, as follows.

\subsubsection{The Effect of Different Strengths of the Mobile Phase.} Under isocratic chromatographic conditions using mobile phase of mixture ACN and $\mathrm{H}_{2} \mathrm{O}$ and Inertsil column (ODS$3250 \mathrm{~mm} \times 4.6 \mathrm{~mm}, 5 \mu \mathrm{m}$ siloxane), different ratios (50\%, $60 \%$, and $70 \% \mathrm{ACN}$ ) were tested. The HPLC chromatograms in Figure 3 show the analysis of $10 \mu \mathrm{g} / \mathrm{mL}$ solution of HCTZ at different strengths of the mobile phase.

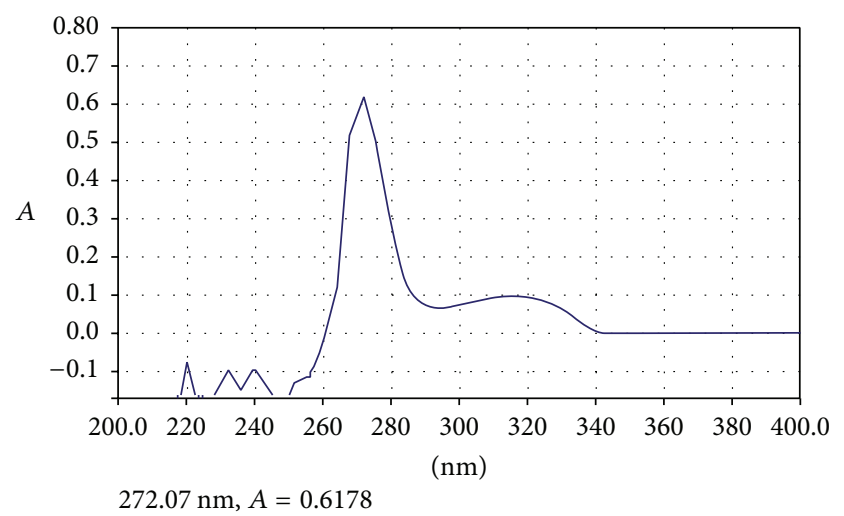

Figure 2: UV-spectrum of HCTZ.

TABLE 1: The effect of different mobile phase strengths on the peak area and retention time of HCTZ.

\begin{tabular}{lcc}
\hline Mobile phase $\left(\mathrm{ACN}: \mathrm{H}_{2} \mathrm{O}\right)$ & $t_{r}(\mathrm{~min})$ & Peak area \\
\hline $50: 50$ & 3.37 & 384763 \\
$60: 40$ & 3.14 & 386386 \\
$70: 30$ & 3.01 & 390123 \\
\hline
\end{tabular}

The results presented in Figure 3 and Table 1 show good shape of eluted peak of HCTZ at all concentrations of the mobile phase and no disturbance in the baseline is observable along the chromatographic record. A little decreasing in retention time and increasing of peak area of HCTZ occur within increasing of mobile phase $(50 \%, 60 \%$, and $70 \%)$ of ACN.

From economic point of view, to avoid waste of ACN solvent, $50 \%$ of ACN was selected as concentration of the mobile phase in this method with approximately $3.5 \mathrm{~min}$ retention time of HTCZ peak and 5 min chromatographic runtime. Taking into account that the column hold-up is about $2.5 \mathrm{~mL}$ for these columns $(25 \times 0.46 \mathrm{~cm})$, so it is advisable to use the weakest eluent.

3.2.2. The Effect of Injection Volume. Three injection volumes of 10,20 , and $30 \mu \mathrm{L}$ were examined through injecting $10 \mu \mathrm{g} / \mathrm{mL}$ of HCTZ. The results shown in Table 2 indicated that the retention time shows small decreasing and the peak area increases with the increase of the injection volume. Injecting a very large volume, the column can be overloaded, which will lead to peak broadening, most often peak fronting, or, in some cases, peak tailing $[17,18]$. This problem limits the injection volume to less than $25 \mu \mathrm{L}$ for columns with $0.46 \mathrm{~cm}$ internal diameter [11]. In this study, the autosampler was set up for a $20 \mu \mathrm{L}$ injection volume to overcome the probability of peak distortion.

3.2.3. The Effect of Column Temperature. The effect of column temperature was studied testing three different temperatures: 30 (ambient), 35, and $40^{\circ} \mathrm{C}$. The results show that there was no big effect on eluted peak of HCTZ showing nearly close retention times $(\sim 3.5 \mathrm{~min})$ and peak areas. Therefore, column oven was set at ambient temperature $\left(30^{\circ} \mathrm{C}\right)$ in this study. 


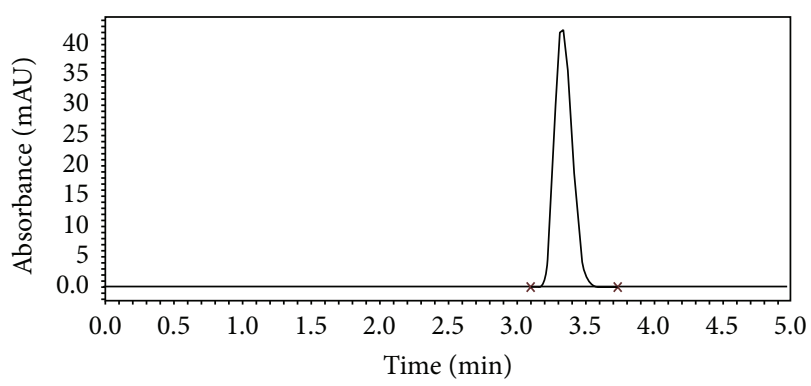

(a)

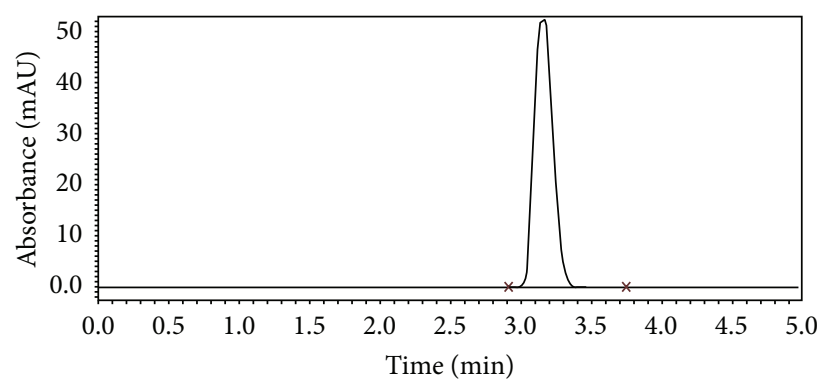

(b)

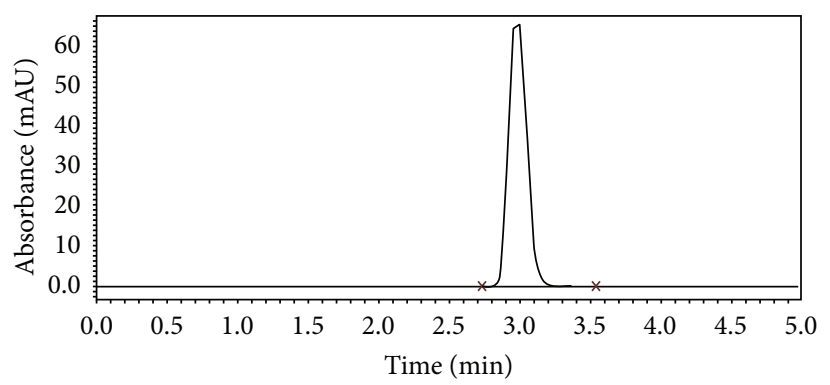

(c)

Figure 3: Chromatogram of HCTZ $(10 \mu \mathrm{g} / \mathrm{mL})$ with mobile phase of $\mathrm{ACN}: \mathrm{H}_{2} \mathrm{O}$ at (a) $50: 50$, (b) $60: 40$, and (c) $70: 30$ (v/v).

TABLE 2: Effect of injection volume on peak area and retention time of HCTZ peak.

\begin{tabular}{lcc}
\hline Injection volume $(\mu \mathrm{L})$ & $t_{r}(\min )$ & Peak area \\
\hline 10 & 3.41 & 192007 \\
20 & 3.36 & 384602 \\
30 & 3.33 & 574737 \\
\hline
\end{tabular}

3.2.4. The Effect of Column. To compare the efficiency of $\mathrm{C}_{18}$ Inertsil column (ODS-3 $250 \mathrm{~mm} \times 4.6 \mathrm{~mm}, 5 \mu \mathrm{m}$ siloxane), another column $\mathrm{C}_{18}$ Zorbax (Eclipse Plus, $4.6 \times 250 \mathrm{~mm}$, $5 \mu \mathrm{m})$ was tested. Figure 4 shows the chromatograms of injection solution of $10 \mu \mathrm{g} / \mathrm{mL}$ of HCTZ on the two columns; under the HPLC conditions they showed a little difference in $t_{r}$ values.

As shown in Figure 4, a narrow and symmetrical peak was obtained on both columns but with a small decreasing in the retention time with little decreasing in the peak area of HCTZ using tested column of Zorbax compared with Inertsil column. A possible explanation for this might be due to the age of the column; Inertsil column is used from long time compared with Zorbax column.

3.3. Method of Validation. Validation of the analytical method prior to determining HCTZ in dosage sample was done by examining such parameters of precision, linearity, and LOD and LOQ using two columns as follows.

3.3.1. Assessment of the Precision of Analytical Method. Repeatability of the method was checked by replicate injections of $5 \mu \mathrm{g} / \mathrm{mL}$ of the solution for five times on the same day as intraday precision study of HCTZ using two

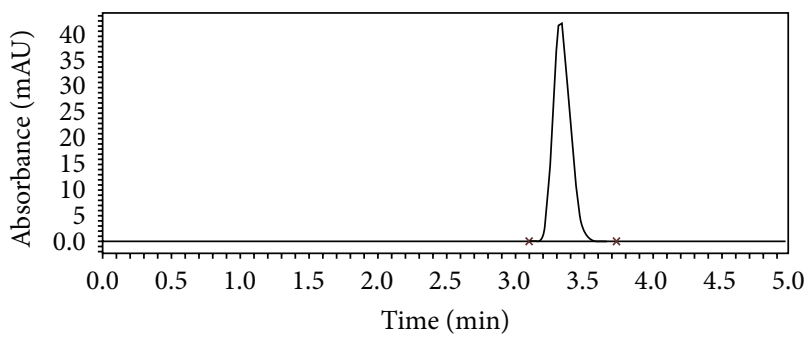

(a)

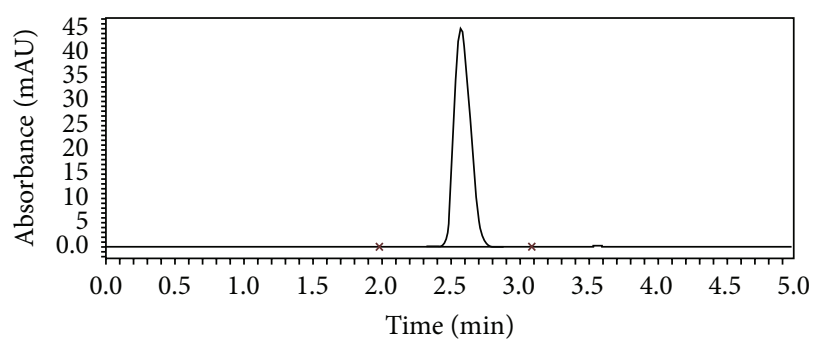

(b)

Figure 4: Chromatogram of $10 \mu \mathrm{g} / \mathrm{mL}$ of HCTZ using (a) Inertsil column and (b) Zorbax column.

columns. \%RSD values were found to be 0.53 and 0.62 on the Inertsil and Zorbax columns, respectively, indicating a good precision of the HPLC method.

3.3.2. Linearity of the Calibration Curve. Linearity of the calibration curve was determined at two ranges of concentrations (2.0-10 and $10-30 \mu \mathrm{g} / \mathrm{mL})$ of HCTZ using two columns. The values of coefficient of determination $\left(R^{2}\right)$ were found to be 


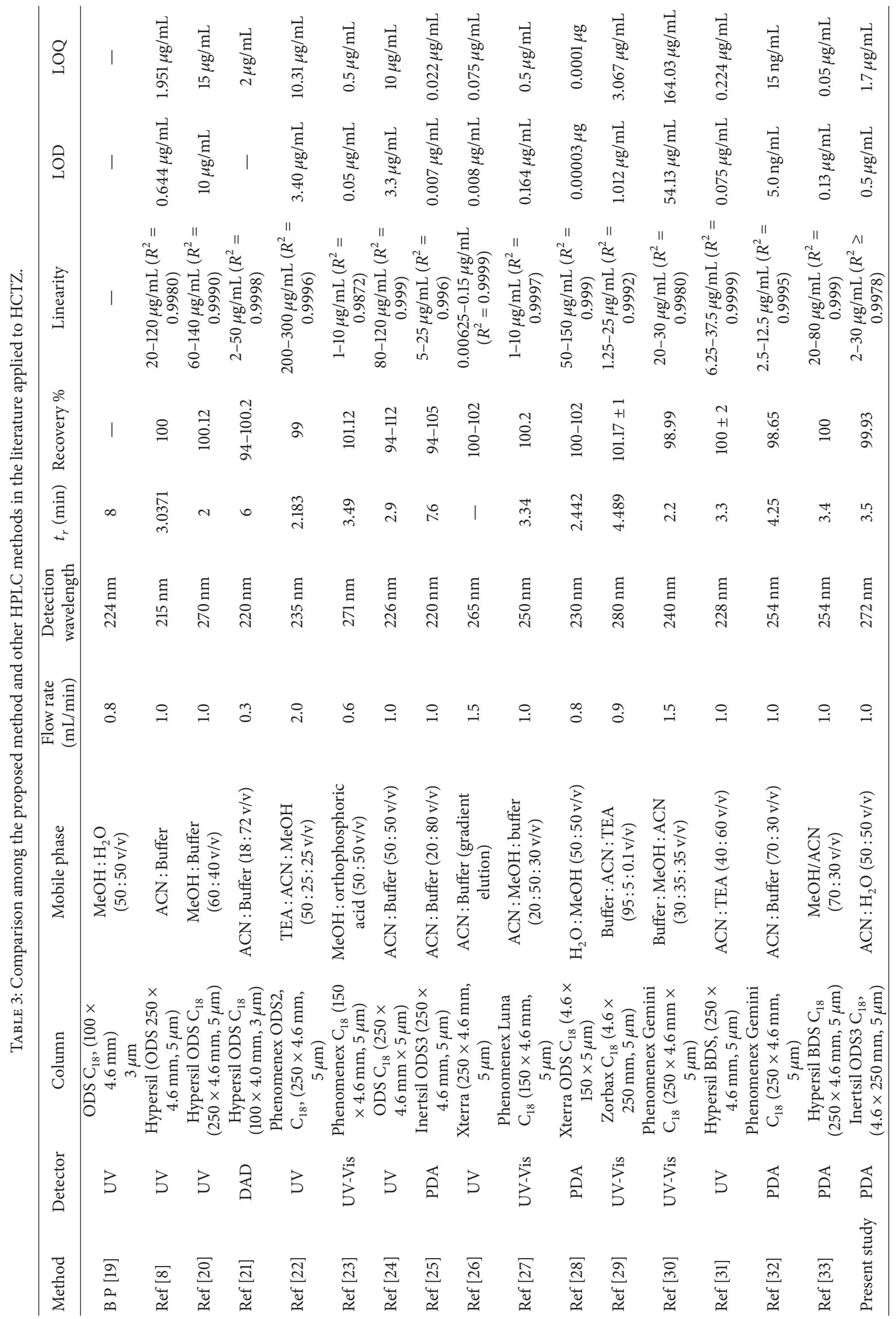


acceptable $\geq 0.9978$ showing good linearity over the ranges studied of the assay method on both columns.

3.3.3. LOD and LOQ Determination. The LOD and LOQ were determined for the analytical method using two columns by the statistical data of calibration curve at low level of the concentrations. The results obtained showed values of LOD and LOQ of 0.5 and $1.7 \mu \mathrm{g} / \mathrm{mL}$, respectively, and these values are close for both columns.

3.3.4. Application of the Method to Dosage Form. The proposed method was applied successfully for the determination of the HCTZ drug in its pharmaceutical dosage. This application was done using Inertsil column. The recovery calculated was equal to $99.93 \%$ with RSD\% of $0.89(n=3)$ indicating that the proposed method is applicable for the determination of HCTZ in pharmaceutical dosage form.

3.4. Comparison with Other Methods. In reviewing the literature, the present method for the determination of HCTZ was compared with other methods as shown in Table 3. Under the chromatographic conditions applied in the present method using a new Perkin Elmer HPLC system coupled with PDA detector, the proposed method shows short retention time and run time with high recovery of HCTZ.

\section{Conclusion}

An RP-HPLC method coupled with PDA detector was developed and validated for the determination of HCTZ in bulk drug and pharmaceutical dosage form. The selected chromatographic conditions were 50:50 acetonitrile: water as a mobile phase, $\mathrm{C}_{18}$ Inertsil ODS-3 column $(4.6 \times 250 \mathrm{~mm}$, $5 \mu \mathrm{m})$, and $20 \mu \mathrm{L}$ injection volumes with flow rate of $1 \mathrm{~mL} / \mathrm{min}$ applied at ambient temperature $\left(30^{\circ} \mathrm{C}\right)$ and $272 \mathrm{~nm}$ wavelength. Testing another column of $\mathrm{C}_{18}$ Zorbax (Eclipse Plus, $4.6 \times 250 \mathrm{~mm}, 5 \mu \mathrm{m}$ ), which has same type of stationary phase of siloxane as $\mathrm{C}_{18}$ Inertsil but with different manufacture, shows no big difference in the method results. Validation parameters indicated a good precision and linearity with low values of LOD and LOQ (approximately 0.5 and $1.5 \mu \mathrm{g} / \mathrm{mL}$, resp.). The application of the proposed method on pharmaceutical dosage of tablet gave recovery of $99.93 \%$. The proposed method is economic, simple, and rapid and hence can be employed for routine analysis in quality control laboratories.

\section{Competing Interests}

The authors declare that there are no competing interests regarding the publication of this paper.

\section{References}

[1] British Pharmacopoeia, vol. 1, The Stationery Office, London, UK, 2007.

[2] P. Pickkers, R. S. Garcha, M. Schachter, P. Smits, and A. D. Hughes, "Inhibition of carbonic anhydrase accounts for the direct vascular effects of hydrochlorothiazide," Hypertension, vol. 33, no. 4, pp. 1043-1048, 1999.

[3] M. A. Gotardo, L. Pezza, and H. R. Pezza, "Determination of hydrochlorothiazide in pharmaceutical formulations by diffuse reflectance spectroscopy," Eclética Química, vol. 30, no. 2, pp. 17-24, 2005.

[4] S. A. Hapse, V. S. Wagh, P. T. Kadaskar, M. D. Dokhe, and A. S. Shirsath, "Spectrophotometric estimation and validation of hydrochlorothiazide in tablet dosage forms by using different solvents," Der Pharma Chemica, vol. 4, no. 1, pp. 10-14, 2012.

[5] A. M. Idris and R. E. E. Elgorashe, "Sequential injection chromatography with a miniaturized multi-channel fiber optic detector for separation and quantification of propranolol and hydrochlorothiazide," Chemistry Central Journal, vol. 5, article 28, pp. 1-8, 2011.

[6] P. N. Bhoya, E. M. Patelia, and Gautambhai, "Development and validation of TLC-densitometry method for simultaneous estimation of Bisoprolol fumarate and hydrochlorothiazide in bulk and tablets," Journal of Chromatography and Separation Techniques, vol. 4, no. 1, article 163, 4 pages, 2013.

[7] S. Gayathri, D. Sireesha, M. A. Haque, S. Harshini, V. Bhakshi, and S. K. Reddy, "Method development and validation of RP-HPLC method for simultaneous estimation of Olmesartan medoxomil and Hydrochlorothiazide in bulk and pharmaceutical dosage form," International Journal of Pharma Research and Health Sciences, vol. 2, no. 6, pp. 457-462, 2014.

[8] M. Mahesh, R. Kumanan, and K. N. Jayaveera, "Isocratic RPHPLC UV Method development and validation for the simultaneous estimation of hydrochlorothiazide and Ramipril in tablet dosage form and bulk durg," International Journal of Current Pharmaceutical Research, vol. 3, no. 2, pp. 119-123, 2011.

[9] Z. Vujić, N. Mulavdić, M. Smajić, J. Brborić, and P. Stankovic, "Simultaneous analysis of irbesartan and hydrochlorothiazide: an improved HPLC method with the aid of a chemometric protocol," Molecules, vol. 17, no. 3, pp. 3461-3474, 2012.

[10] B. V. Savaj, H. A. Raj, S. Rajanit, and S. Harshita, "Analytical techniques for determination of hydrochlorothiazide and its combinations: a review," International Journal of Advances in Scientific Research, vol. 1, no. 3, pp. 114-128, 2015.

[11] L. R. Snyder, J. J. Kirkland, and J. L. Glajch, Practical HPLC Method Development, John Wiley \& Sons, New York, NY, USA, 2nd edition, 1997.

[12] J. W. Dolan, "Temperature selectivity in reversed-phase high performance liquid chromatography," Journal of Chromatography A, vol. 965, no. 1-2, pp. 195-205, 2002.

[13] J. N. Miller and J. C. Miller, Statistics and Chemometrics for Analytical Chemistry, Pearson Prentice Hall, Harlow, UK, 2005.

[14] R. Gangola, S. Kaushik, and P. Sharma, "Spectrophotometric simultaneous determination of Hydrochlorothiazide and Telmisartan in combined dosage form," Journal of Applied Pharmaceutical Science, vol. 1, no. 1, pp. 46-49, 2011.

[15] V. K. Redasani, P. V. Patel, and S. J. Surana, "Spectrophotometric method for simultaneous estimation of Valsartan and Hydrochlorothiazide in combined tablet dosage form," Der Pharmacia Sinica, vol. 2, no. 3, pp. 123-130, 2011.

[16] K. Ilango and P. S. Shiji Kumar, "Simultaneous determination of olmesartan medoxomil and hydrochlorothiazide by area under curve and dual wavelength spectrophotometric methods," Journal of Pharmaceutical Sciences and Research, vol. 4, no. 10, pp. 1946-1949, 2012.

[17] S. Keunchkarian, M. Reta, L. Romero, and C. Castells, "Effect of sample solvent on the chromatographic peak shape of 
analytes eluted under reversed-phase liquid chromatogaphic conditions," Journal of Chromatography A, vol. 1119, no. 1-2, pp. 20-28, 2006.

[18] U. D. Neue, HPLC Columns; Theory, Technology, and Practice, Wiley-VCH, New York, NY, USA, 1997.

[19] R. Gaur, M. Azizi, J. Gan et al., British Pharmacopoeia, 2009.

[20] S. Bhagwate and N. J. Gaikwad, "Stability indicating HPLC method for the determination of hydrochlorothiazide in pharmaceutical dosage form," Journal of Applied Pharmaceutical Science, vol. 3, no. 2, pp. 88-92, 2013.

[21] V. Ivanova, D. Zendelovska, and M. Stefova, "HPLC determination of Hydrochlorothiazide in urine after solid-phase extraction," Macedonian Pharmaceutical Bulletin, vol. 51, no. 1-2, pp. 23-28, 2005.

[22] K. Safeer, B. Anbarasi, and N. S. Kumar, "Analytical method development and validation of amlodipine and hydrochlorothiazide in combined dosage form by RP-HPLC," International Journal of ChemTech Research, vol. 2, no. 1, pp. 21-25, 2010.

[23] K. Prameela, T. Santosh, and K. H. Baba, "Development and Validation of a stability indicating method for the simultaneous determination of Atenolol and Hydrochlorothiazide by HPLC," International Journal of Pharmaceutics and Drug Analysis, vol. 1, no. 1, pp. 49-60, 2013.

[24] V. Chaudhari, S. Hussian, and M. Ubale, "A newer validated and stability indicating HPLC method forthe estimation of Atenolol and Hydrochlorothiazide in bulk drug and dosage form," International Journal of Chemical Studies, vol. 1, no. 4, pp. 93-101, 2013.

[25] V. Leela Padmini, S. K. Firdose, S. Madhavi, M. Javed Mohammed, and B. N. Nalluri, "Simultaneous estimation of lisinopril and hydrochlorthiazide in bulk, pharmaceutical dosage forms and in dissolution samples by RP-HPLC-PDA method," Journal of Chemical and Pharmaceutical Research, vol. 5, no. 8, pp. 195-202, 2013.

[26] M. Kharoaf, N. Malkieh, M. Abualhasan, R. Shubitah, N. Jaradat, and A. N. Zaid, "Tablet formulation and development of a validated stability indicating HPLC method for quantification of valsartan and hydrochlorthiazide combination," International Journal of Pharmacy and Pharmaceutical Sciences, vol. 4, no. 3, pp. 284-290, 2012.

[27] D. Jothieswari, D. Priya, S. Brito Raja, E. Mohanambal, and S. Wasim Raja, "Design and RP-HPLC method for the simultaneous determination of valsartan and hydrochlorothiazide in bulk and in pharmaceutical formulation," International Journal of Novel Trends in Pharmaceutical Sciences, vol. 1, no. 1, pp. 1822, 2011.

[28] M. R. Bhimavarapu, "Method development and validation for the simulataneous estimation of atenolol and hydrochlorthiazide in tablet dosage form by RP-HPLC method," International Journal of Advances in Pharmaceutical Sciences, vol. 3, no. 3-4, pp. 204-210, 2012.

[29] R. I. El-Bagary, E. F. Elkady, and A. J. Faqeh, "Simultaneous determination of atenolol, amiloride hydrochloride and hydrochlorothiazide using reversed phase liquid chromatography," Journal of Chemical and Pharmaceutical Research, vol. 3, no. 6, pp. 320-329, 2011.

[30] O. J. Aboobacker, T. Venkatachalam, N. Senthilkumar, R. Vijayamiruthraj, and P. Kalaiselvi, "Method development and validation of hydrochlorothiazide, amlodipine besylate and telmisartan in tablet dosage form by RP-HPLC method," Research Journal of Pharmaceutical, Biological and Chemical Sciences, vol. 3, no. 3, pp. 509-517, 2012.
[31] V. K. Rekulapall and V. U. Rao, "Stability indicating RpHplc method development and validation for simultaneous estimation of aliskiren, amlodipine and hydrochlorthiazide in tablet dosage form," International Journal of Pharmacy and Pharmaceutical Sciences, vol. 6, no. 1, pp. 724-730, 2014.

[32] S. N. Meyyanathan, S. Rajan, S. Muralidharan, A. S. Birajdar, and B. Suresh, "A validated RP-HPLC method for simultaneous estimation of nebivolol and hydrochlorothiazide in tablets," Indian Journal of Pharmaceutical Sciences, vol. 70, no. 5, pp. 687689, 2008.

[33] M. Rudrapal, M. U. Oduri, N. R. Samidala et al., "Development and validation of RP-HPLC method for simultaneous estimation of olmesartan and hydrochlorothiazide in tablet dosage form," Oriental Journal of Chemistry, vol. 31, no. 2, pp. 921-926, 2015. 

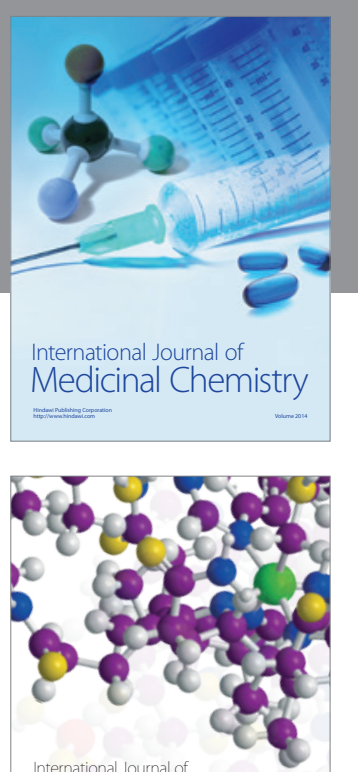

Carbohydrate Chemistry

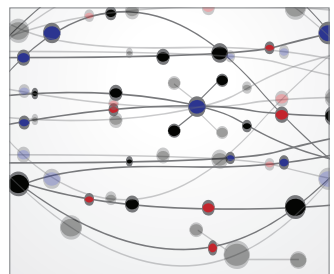

The Scientific World Journal
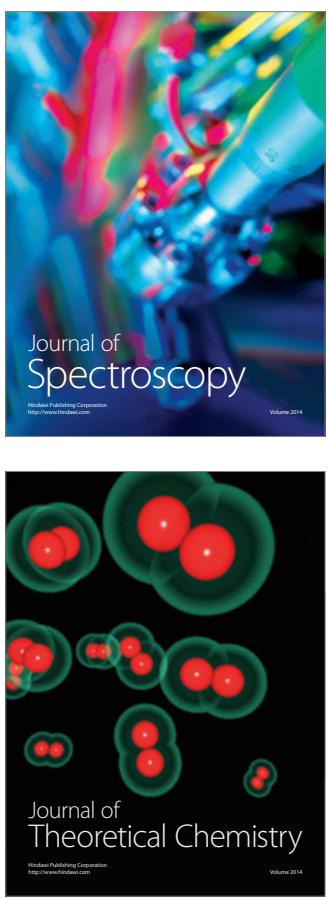
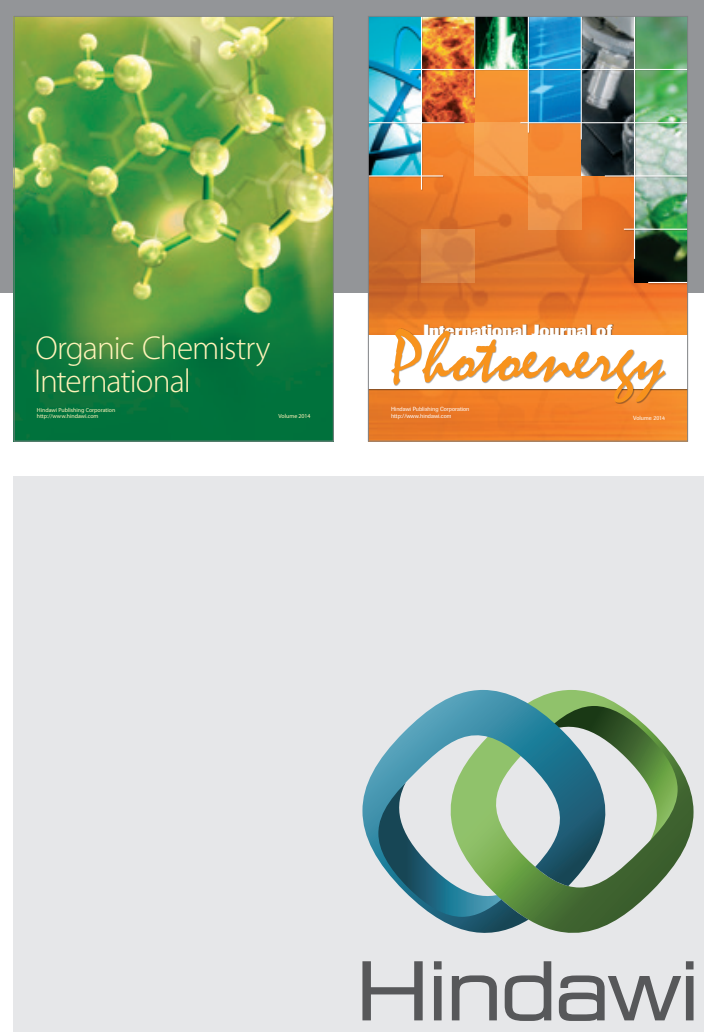

Submit your manuscripts at

http://www.hindawi.com

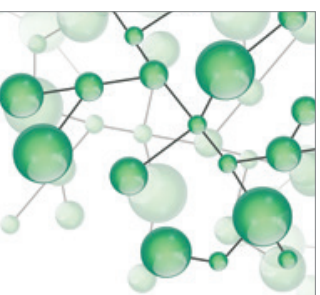

International Journal of

Inorganic Chemistry

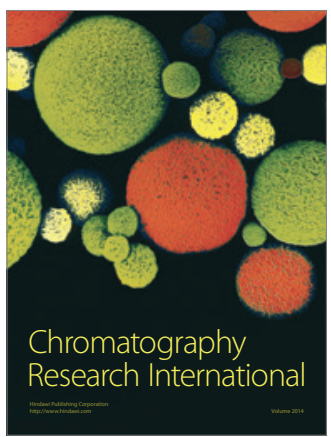

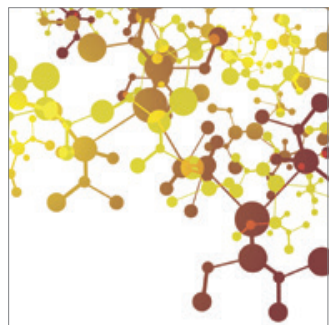

Applied Chemistry
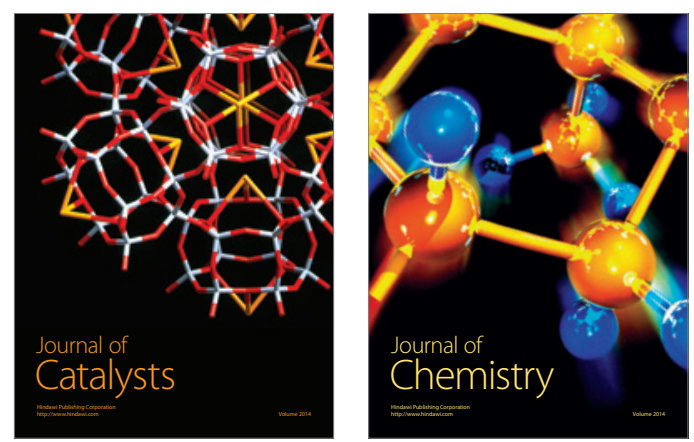
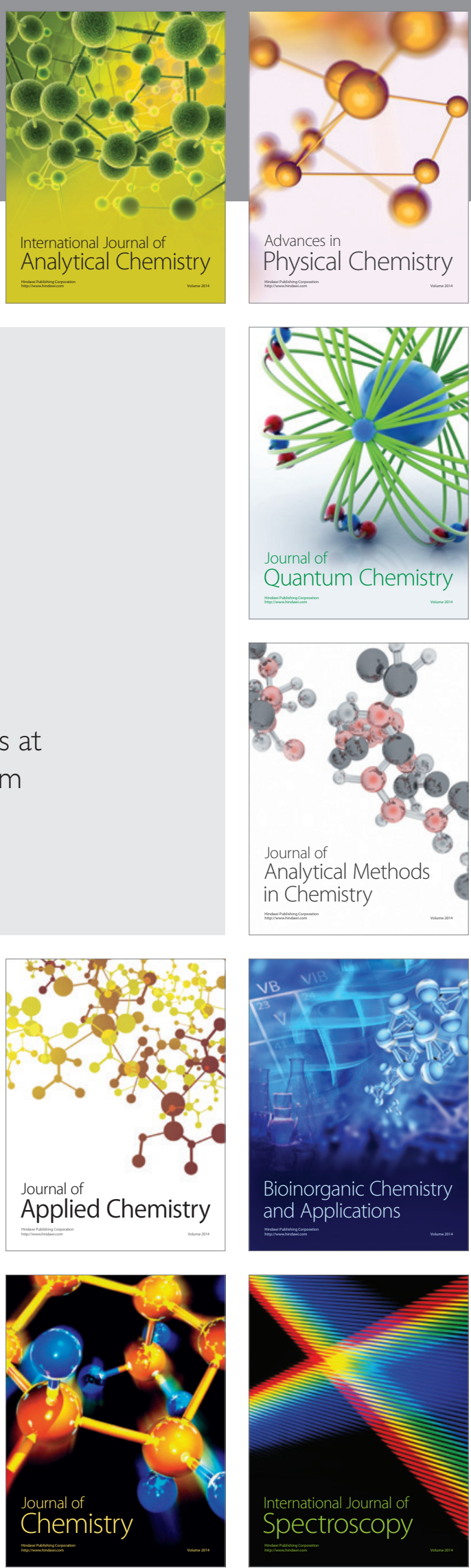